\title{
Las condiciones laborales de las temporeras magrebíes en los campos de Huelva
}

\author{
The working conditions of the Maghreb temporary \\ workers in the Huelva camps
}

\author{
ILHAME ECHAJRI AMHAOUCH \\ Doctoranda en Derecho del Trabajo y de la Seguridad \\ Social \\ Universidad de Murcia
}

Recibido: 8/1/2020

Aceptado: $22 / 12 / 2020$

doi: https://doi.org/10.20318/femeris.2021.5934

Resumen. No habrá desarrollo ni progreso humano sin igualdad real y efectiva de oportunidades entre hombres y mujeres. Por ello, toda actuación de los poderes públicos encaminada a garantizar la igualdad entre ambos sexos tendrá un efecto multiplicador que impulsará mejoras sociales y económicas a todos los niveles, beneficiando de forma especial a las mujeres más desprotegidas, entre las que se encuentran, sin duda, las trabajadoras extranjeras. El presente artículo se centra en un concreto colectivo de mujeres inmigrantes, víctimas de duras condiciones de vida y de trabajo, así como, en ocasiones, de distintos grados de violencia sexual. Me refiero a las trabajadoras, principalmente de nacionalidad magrebí, que cada año llegan a los campos de Huelva para trabajar en la plantación y/o recolección de fresas, frambuesas y arándanos. Se analizará, particularmente, la dudosa fórmula de contratación en origen utilizada, y como la misma contribuye a la precariedad laboral y vital extrema sufrida por estas mujeres.

Palabras clave: mujer magrebí, igualdad, discriminación, derecho y precariedad laboral..

Abstract. There will be no development or human progress without real and effective equality of opportunities between men and women. Therefore, any action by the public authorities to ensure equality between the sexes will have a multiplier effect that will drive social and economic improvements at all levels, particularly benefiting the most unprotected women, among which foreign workers are undoubtedly. This article focuses on a collective concrete number of immigrant women, victims of harsh living and working conditions, as well as sometimes different degrees of sexual violence. I am referring to the workers, mainly of Maghreb nationality, who every year arrive in the fields of Huelva to work on the plantation and /or harvesting of strawberries, raspberries and blueberries. The dubious recruitment formula used will be analysed in particular, and how it contributes to the extreme occupational and vital precariousness suffered by these women.

Keywords: Maghreb woman, equality, discrimination, employment rights and precariousness.

*echajriilhame@gmail.com 


\section{Introducción}

En los campos de Huelva el cultivo de frutos rojos se desarrolla de manera intensiva, destinada a la exportación hacia los mercados europeos, como Francia, Reino Unido, Bulgaria o Bélgica, o los mercados asiáticos, como China ${ }^{1}$. De esta manera, cabe decir que el cultivo y/o recolección de frutos rojos en los campos onubenses se ha convertido en la primera potencia productora y exportadora a Europa, así como la segunda a escala mundial detrás de California².

El crecimiento del sector agrícola onubense, acompañado de factores como: el éxodo rural y el abandono de los trabajos campestres, ha conducido que entre los años 2000 y 2001 los actores estatales y no estatales comiencen a contratar intensamente mano de obra de origen extranjero con la finalidad de cubrir empleos vacantes.

Las campañas temporales de la plantación y/o recolección se producen en varios meses del año (entre enero y julio de cada año), en los que se necesita abundante mano de obra. Con la finalidad de cubrir esta mano de obra muchas empresas del sector acuden a la contratación de trabajadoras extranjeras con la consiguiente finalidad de sacar adelante la campaña y conseguir el máximo beneficio, con demasiada frecuencia, a costa del sacrificio de los derechos laborales y de seguridad social de este colectivo.

De ahí se recurrió a la utilización de la fórmula de contratación en origen que se ha convertido en una herramienta de cobertura legal que permite a las empresas del sector el correcto funcionamiento y desarrollo de la campaña agrícola onubense.

Es en el año 2001 cuando el Gobierno español, a través de un Acuerdo negociado con Marruecos $^{3}$, ha adoptado el sistema de contratación en origen destinado a una elevada cifra de trabajadoras ${ }^{4}$; son alrededor de 19.000 los contratos que estaban previstos para el año $2019^{5}$. Estas contrataciones en origen incluyen un conjunto de exigentes requisitos tales como el compromiso de retorno que obliga a las trabajadoras a regresar a Marruecos una vez concluida la campaña, o ser mujeres de entre 25 y 45 años para poder responder a las exigencias físicas de la plantación y recolección de la fresa, frambuesa o arándanos. Como apunta Manuel Piedra, secretario general de la UPA-Huelva: "Si no tuviéramos la contratación en origen en Marruecos no podríamos recolectar toda la fruta que hay". En

\footnotetext{
${ }^{1}$ Viveros California. (2017). El mercado Asiático quiere fresas andaluzas. Recuperado de http://viveroscalifornia. com/noticias/mercado-asiatico-plantas-fresa (En línea).

${ }^{2}$ Macías Llaga, I, Márquez Domínguez, J.A y Jurado Almonte J.M. (2016). La contratación en origen de temporeros marroquíes para los campos españoles como experiencia de codesarrollo. Recuperado de https://revistaseug.ugr.es/index. php/cuadgeo/article/view/3910/5149 (En línea).

${ }^{3}$ Acuerdo celebrado por el Ministerio Español de Asuntos Sociales, las principales organizaciones de agricultores de la fresa de Huelva y la Agencia Nacional de Empleo de Marruecos presidida por Abdeallah Benkirane (ANAPEC). Véase, la Aplicación Provisional del Acuerdo sobre mano de obra entre el Reino de España y el Reino de Marruecos, celebrado en Madrid el 25 de julio de 2001, con entrada en vigor en septiembre de 2005 (publicado en el BOE núm. 226, de 20 de septiembre de 2001). Recuperado de https://www.boe.es/diario_boe/txt.php?id=BOE-A-2001-17764 (En línea).

${ }^{4}$ La Vanguardia. (2018). Más de 18.000 temporeras marroquíes viajan este año a España a recoger fresa. Recuperado de http://www.lavanguardia.com/vida/20180125/44280770931/mas-de-18000-temporeras-marroquies-viajaneste-ano-a-espana-a-recoger-fresa.html (En línea).

${ }^{5}$ ABDdesevilla. (2009). El Gobierno autoriza 19.000 temporeras marroquíes en Huelva. Recuperado de https://sevilla.abc.es/andalucia/huelva/sevi-gobierno-autoriza-19000-temporeras-marroquies-huelva-201911020821_noticia. html (En línea).
} 
términos similares se pronuncia Antonio Agustín Vázquez, Delegado Territorial de Empleo de la Junta de Andalucía, quien considera que "la contratación en origen es absolutamente necesaria porque se necesita un volumen muy alto de jornales en un período especialmente corto que no se puede completar con personas comunitarias"6.

La producción en el año 2018 se situó cerca de 280.300 toneladas de fresa; 19.170 toneladas de frambuesa; 30.000 toneladas de arándanos y 1.800 toneladas de moras; la facturación de la pasada campaña asciende a un total de 437.268.00 euros, en buena medida, gracias al trabajo precario de la mano de obra extranjera. El sector fresero de Huelva cerró la campaña 2018-2019 con una producción total de fresa de 341.556 toneladas, de las que más del 70\% fueron exportadas a países extranjeros, principalmente de la Unión Europea. El principal socio comercial es Alemania, que en esta última campaña absorbió el 31,7 \% de las exportaciones andaluzas de fresa. Le siguieron Reino Unido $(15,5 \%)$, Francia $(14,6 \%)$ e Italia $(10,3 \%)$ como principales destinatarios; a distancia se encuentran Portugal, Países Bajos, Austria o Bélgica, con volúmenes por encima de las 8.000 toneladas $^{7}$.

Llegados a este punto, cabe preguntarse: ¿Por qué esta necesidad de mano de obra no se cubre con demandantes de empleo autóctono? ¿Por qué sólo se selecciona a mujeres y extranjeras? ¿Cuáles son las condiciones laborales y vitales que debe soportar este colectivo?

Estas son algunas de las dudosas cuestiones que se suscitan en la actualidad, y a las que se intentará, en la medida de lo posible, dar objeción en el presente artículo.

\section{La inmigración en España}

\subsection{Planteamiento}

La inmigración ha sido una realidad continua desde los orígenes de la Humanidad, que siempre ha significado una aportación de gran valor, un factor de crecimiento económico y cultural, así como una contribución de innovación para los territorios receptores de capital humano. Ahora bien, el aspecto económico de la inmigración no debe hacer pasar por alto la importancia y centralidad del fenómeno desde la perspectiva de los derechos humanos, intrínsecos a todas las personas, independientemente de su valor instrumental como unidades laborales o agentes del desarrollo ${ }^{8}$. Al respecto, el art. 13 de la Declaración

\footnotetext{
${ }^{6}$ Cope. (2019). La contratación en origen es imprescindible para la campaña agrícola. Recuperado de https://www. cope.es/emisoras/andalucia/huelva-provincia/huelva/noticias-agrarias/noticias/contratacion-origen-imprescindible-para-campana-agricola-20191108_546411 (En línea).

${ }^{7}$ ABDdesevilla. (2009). El Gobierno autoriza 19.000 temporeras marroquíes en Huelva. Recuperado de https://sevilla.abc.es/andalucia/huelva/sevi-gobierno-autoriza-19000-temporeras-marroquies-huelva-201911020821_noticia. html (En línea).

${ }^{8}$ Migración y derechos humanos: Mejora de la Gobernanza basada en los derechos humanos de la inmigración internacional. Oficina del Alto Comisionado para los Derechos Humanos, Ginebra, Suiza. Recuperado de https://www.ohchr. org/Documents/Issues/Migration/MigrationHR_improvingHR_ReporSPt.pdf (En línea).
} 
Universal de Derechos Humanos establece lo siguiente": 1. "Toda persona tiene derecho a circular libremente y a elegir su residencia en el territorio de un Estado. 2. Toda persona tiene derecho a salir de cualquier país, incluso del propio, y a regresar a su país".

Desde el primer semestre de 2018 desembarcaron en Italia, procedentes mayoritariamente de Libia, 11.288 inmigrantes, mientras que a España llegaron desde Marruecos, a través de Ceuta y Melilla, 15.441 inmigrantes, según fuentes del Ministerio del Interior español. España sufre un fenómeno migratorio agravado respecto al resto de países de la UE. La cifra de personas inmigrantes que han accedido en el año 2018 a España de manera irregular duplica la cifra del año $2017^{10}$.

La ruta migratoria clandestina del Mediterráneo Occidental es la única vía que está en auge, en relación a las restantes rutas de Italia o Grecia. La frontera sur de España, que separa Marruecos de los enclaves de Ceuta y Melilla, se convierte en la principal vía de entrada para la inmigración irregular ${ }^{11}$.

España ha sido uno de los países miembros de la Unión Europea que ha recibido en los últimos tiempos un mayor porcentaje de personas extranjeras junto a Italia, Alemania, Francia o Grecia. En este sentido, y según fuentes del INE, desde el año 2009 y hasta el año 2018, la población inmigrante procedente del continente africano registró un paulatino crecimiento, con un total de 1.066.029 inmigrantes. Es en el año 2015, cuando se registró un ligero descenso de la entrada de la población africana en España, debido a la crisis económica y a la inestabilidad política ${ }^{12}$.

Estos datos evidencian que la inmigración se ha convertido en España en un fenómeno social de primer orden, con implicaciones de carácter económico, político, demográfico, cultural y religioso ${ }^{13}$.

\subsection{Causas y efectos de la inmigración}

La causa principal que conduce a miles de inmigrantes a poner en riesgo sus vidas, junto a la de sus familiares, son las pésimas condiciones de vida sufridas en sus respectivos países de origen. La pobreza, las guerras, los conflictos armados, la miseria, las hambrunas, la expoliación de recursos naturales, las dictaduras, la exclusión social, la violencia generalizada, las violaciones de derechos humanos, la xenofobia y el subdesarrollo

\footnotetext{
${ }^{9}$ Proclamada por la Asamblea General de las Naciones Unidas en París, el 10 de diciembre de 1948 en su Resolución 217 A (III).

${ }^{10}$ Cembrero, I. (2018). España recibe ya más inmigrantes irregulares de Marruecos que Italia de Libia. Recuperado de https://www.elconfidencial.com/mundo/2018-06-25/espana-recibe-ya-mas-inmigrantes-irregulares-de-marruecosque-italia-de-libia_1583374/ (En línea).

${ }^{11}$ Made for minds. (2016). Entrada masiva de inmigrantes por el sur de España. Recuperado de https://www.dw.com/ es/entrada-masiva-de-inmigrantes-por-el-sur-de-espa\%C3\%B1a/a-19210253 (En línea).

${ }^{12}$ Instituto Nacional de Estadística. (2019). Población extranjera por Nacionalidad, comunidades, Sexo y Año, 20092018. Recuperado de https://www.ine.es/jaxi/Datos.htm?path=/t20/e245/p08/10/\&file=02005.px (En línea).

${ }^{13}$ Bajo Santos, N. (2007). Conceptos y teorías sobre inmigración, Anuario Jurídico y Económico Escurialense, pág. 819. Recuperado de https://www.rcumariacristina.com/wp-content/uploads/2010/12/V-NICOLAS-BAJO-SANTOS.pdf (En línea).
} 
económico que sufre el continente africano son circunstancias más que suficientes para comprender las causas de este fenómeno.

Dadas las pésimas condiciones de vida y trabajo que ofrece el continente africano, muchas personas acuden a la inmigración como única vía para encontrar nuevas oportunidades. Ahora bien, dado que no hay suficientes posibilidades migratorias en condiciones regulares, las personas que se desplazan desde sus países de origen se ven obligadas a recurrir a los canales irregulares de migración, entre ellos: solicitar los servicios de traficantes de personas. Estas condiciones de vulnerabilidad conducen linealmente a este colectivo a situarse ante un riego de experimentar otras situaciones, entre las que se encuentra, la trata de seres humanos con fines de explotación sexual.

Con frecuencia, se deniega el acceso a países de acogida a quienes solicitan asilo y refugio por razón de la inestabilidad política en sus países de origen. Las personas migrantes o solicitantes de asilo y refugio pueden encontrarse desamparados en tránsito, sin posibilidad de avanzar, quedando, a menudo, sometidas a una detención prolongada en el lugar de destino. La mayoría de las personas migrantes que logran acceder a un determinado país, viven y trabajan en condiciones desfavorables de seguridad y dignidad, quedando sometidas a situaciones de violencia, discriminación, xenofobia, y explotación.

Una vez llegadas al país de destino, habida cuenta de la merma de derechos que implica carecer de la ciudadanía de tal país, las personas inmigrantes se enfrentan a una primera etapa de su trayectoria laboral en estado de precariedad e indefensión laboral y social. Este déficit estructural cristaliza en la exclusión laboral, social, cultural y política del colectivo ${ }^{14}$, que provocará una situación de inferioridad, e impedirá alcanzar una protección social digna y adecuada a todo ser humano.

Como se ha señalado anteriormente, la migración que plantea más retos estadísticos para Europa es la procedente de África. Para entender esta realidad, conviene tener en cuenta lo siguiente ${ }^{15}$ :

- Las principales causas de la migración no voluntaria en África son la pobreza ${ }^{16}$, el cambio climático, y la falta de paz y de seguridad política y social.

- El reto demográfico es un hecho: África ha pasado de 477 millones de personas en 1980 a 1.250 millones en 2017, y alcanzará los 2.500 millones en 2050, y todo ello a pesar de su alta tasa de mortalidad, que se compensa con una alta natalidad.

- La UE y, en especial, la Europa meridional es el principal destino permanente de migración africana, por sus bajas tasas de natalidad (ínfimas en el caso de Italia

\footnotetext{
${ }^{14}$ López Pino, C.M. (2004). El mercado laboral de la población inmigrante en España, un estudio de caso, Gestión Humana, pág. 126. Recuperado de http://www.scielo.org.co/pdf/inno/v14n23/v14n23a10.pdf (En línea).

${ }^{15}$ Ministerio de Asuntos Exteriores, Unión Europea y Cooperación. (2018). Las migraciones en África, Documentos Exteriores. Recuperado de http://www.exteriores.gob.es/Portal/es/PoliticaExteriorCooperacion/Africa/Documents/20180724_ARTICULO.pdf (En línea).

${ }^{16}$ Según la Agencia de la ONU, de los 48 países más pobres del mundo, tres cuartas partes están situados en África. Actualmente, África es el escenario de 25 guerras y conflictos activos en el mundo. Recuperado de https://eacnur.org/ es/actualidad/noticias/emergencias/pobreza-en-africa-analizamos-las-principales-causas (En línea).
} 
y España ${ }^{17}$ ), sus relativos altos índices de economía informal, y por el efecto llamada de las crecientes diásporas africanas instaladas en esos países en la última década.

- El principal sector de generación de empleo africano presente y futuro es la agricultura; por ello, la mayoría de la población migrante irregular utiliza los trabajos de la agricultura y la ganadería como fuente de ventaja competitiva.

- El desempleo es la razón principal de la migración regular e irregular; en África, se registran altas tasa de desempleo en la población joven y la femenina. El mercado de trabajo de la mayoría de los países africanos se caracteriza por las condiciones de trabajo que ofrece, que con frecuencia se acercan a las propias de la esclavitud.

- El trabajo infantil, la trata de seres humanos, los denominados delitos de honor, la explotación sexual, la expropiación de los recursos naturales por parte de países desarrollados..., son otras de las muchas causas que provoca la inmigración masiva hacia países de la UE.

\section{La contratación en origen}

La contratación de inmigrantes en los sectores de trabajo que no requieren cualificación, como la manipulación agrícola o el servicio doméstico, se contempla como una necesidad para muchos sujetos empleadores que han de cubrir la demanda de mano de obra en actividades en las que una buena parte la población autóctona no desea trabajar, al ser percibidas como de escaso valor social. En este sentido se ha afirmado que "existe una serie de españoles y españolas sin trabajo que no están dispuestos/as a ganarse la vida limpiando las calles o en la vendimia"18.

Con la llegada de la recesión económica, que supuso un aumento notable de la población desempleada, la población extranjera comenzó a ocupar puestos de trabajo de baja cualificación y alta precariedad ${ }^{19}$; y pese a que la población autóctona también comenzó a ocupar dichos puestos, lo hizo en mejores condiciones que la población extranjera.

\footnotetext{
${ }^{17}$ Según datos del INE, la tasa de natalidad de la población española en el año 2017 ha sido 7,53 nacidos por mil habitantes, mientras que la tasa de la población extranjera duplica más de la mitad a la nacional, con 16,75 nacidos por mil habitantes. Recuperado de http://www.ine.es/jaxiT3/Datos.htm?t=1433 (En línea).

${ }^{18}$ Diario de Burgos. (2010). Los inmigrantes acaparan trabajos que no quieren hacer los españoles. Recuperado de http://www.diariodeburgos.es/noticia.cfm/Economia/20101101/inmigrantes/acaparan/trabajos/no/quieren/hacer/espa\%C3\%B1oles/269FA2B1-F3B6-16DA-A9E0DE8D5083454C (En línea).

${ }^{19}$ Los efectos del desempleo de la población inmigrante se agravan respecto de la población autóctona. A título de ejemplo, entre los requisitos que exigen la Ley Orgánica 4/2000, de 11 de enero, sobre Derechos y Libertades de los Extranjeros en España y su Integración Social (en adelante, LOEXIS) (Arts. 36, 38 y 40), para renovar la autorización de residencia temporal, se encuentran los siguientes: haber ostentado una relación laboral durante un mínimo de seis meses por año, haber concertado un contrato de trabajo, donde el trabajador/a este de alta o situación asimilada al alta o disponer de un nuevo contrato de trabajo que garantice la actividad laboral del trabajador/a y con inicio de vigencia condicionado a la concesión de la renovación. Estos exigentes requisitos han conducido a las personas a optar por cualquier contrato de trabajo, con la finalidad de obtener la autorización de residencia y/ trabajo.
} 
El principal problema que tuvieron que enfrentarse la inmensa mayoría de las personas empresarias fue la necesidad de buscar mano de obra que garantice el cultivo, plantación y recolección de frutos rojos, al tratarse de productos perecederos, y que requieren una recolección precisa, manual y dinámica.

El principio que rige el Derecho de Extranjería, de prioridad del mercado laboral nacional ${ }^{20}$, se ha materializado a través de los "cupos de trabajo", que actúan como un mecanismo regulador de los flujos migratorios no pertenecientes a la UE. Esta política reguladora ofrece anualmente un número máximo de autorizaciones para trabajar en aquellas actividades económicas no cubiertas por la fuerza de trabajo autóctona ${ }^{21}$, fundamentalmente los trabajos en la agricultura y la ganadería; básicamente contempla puestos de trabajo que son difíciles de cubrir por la mano de obra autóctona.

La explotación de la fuerza de trabajo de las personas inmigrantes en el sector agrícola y ganadero, con frecuencia, se acerca a las condiciones propias de la esclavitud. Determinado empresariado se prevalece de la penosa situación de las personas inmigrantes, dado que estas necesitan trabajar para subsistir y enviar recursos a sus países de origen para mantener a sus familiares ${ }^{22}$. Particularmente, los altos niveles de desempleo y la pertenencia a un colectivo mayoritariamente empobrecido, propician que la población marroquí ocupe puestos de trabajo en condiciones laborales precarias, y sean víctimas de situaciones discriminatorias.

Ello no obstante, el Acuerdo sobre mano de obra entre el Reino de España y el Reino de Marruecos, adoptado en 2001, establece en su art. 6 que "los trabajadores y trabajadoras marroquíes gozarán de los derechos y privilegios que les conceda la legislación española" y que "las autoridades competentes se comprometen en este contexto a tomar las medidas necesarias para facilitar el acceso a una mejor cualificación profesional de esos trabajadores y trabajadoras". Entre otros objetivos marcados por este Acuerdo bilateral, se hace especial énfasis en el deseo de reforzar los vínculos de cooperación y amistad existentes entre las dos partes contratantes, y de unir los esfuerzos a los realizados en el ámbito internacional con la finalidad de prevenir la explotación laboral de personas extranjeras.

Como se podrá observar en las tablas de la página siguiente, las nacionalidades que protagonizaron el contingente de contratación en origen fueron Rumania, Polonia y Marruecos, ocupando en menor medida Filipinas y Ucrania. Con el discurrir de los años, las nacionalidades que participaron inicialmente en las sucesivas campañas comenzaron a perder peso, como es el caso de Polonia, Bulgaria o Rumanía, situándose Marruecos en una constante línea ascendente dada su proximidad geográfica, quien en el 2009 alcanzo cerca de 14.190 contratos de trabajo. En el caso de Rumania, Polonia y Bulgaria protagonizaron en mayor o menor medida la contratación en origen. Asimismo, y como consecuen-

\footnotetext{
${ }^{20}$ Selma Penalva, A. (2013). La protección jurídico-social de los colectivos especialmente vulnerables. Pág. 211. Murcia, España: Servicio de Publicaciones de la Universidad de Murcia (EDITUM).

${ }^{21}$ Regulado en el Art. 38.1 LOEXIS: Para la concesión inicial de la autorización de residencia y trabajo, en el caso de trabajadores por cuenta ajena, se tendrá en cuenta la situación nacional de empleo.

${ }^{22}$ ABC. (2016). Explotación de inmigrantes en el campo: seis euros al día y heridas en las manos. Recuperado de http://www.abc.es/espana/comunidad-valenciana/abci-explotacion-inmigrantes-campo-seis-euros-y-heridas-manos-201612031200_noticia.html (En línea).
} 
Tabla 1. Contratación de temporeras/os a través del contingente/CEGCCO en la provincia de Huelva por nacionalidad y campaña.*

\begin{tabular}{|l|c|c|c|c|c|c|c|c|c|c|c|c|c|c|}
\hline Países & $\mathbf{2 0 0 0 /}$ & $\mathbf{2 0 0 1 /}$ & $\mathbf{2 0 0 2 /}$ & $\mathbf{2 0 0 3 /}$ & $\mathbf{2 0 0 4 /}$ & $\mathbf{2 0 0 5 /}$ & $\mathbf{2 0 0 6 /}$ & $\mathbf{2 0 0 7 /}$ & $\mathbf{2 0 0 8 /}$ \\
$\mathbf{2 0 0 1}$ & $\mathbf{2 0 0 2}$ & $\mathbf{2 0 0 3}$ & $\mathbf{2 0 0 4}$ & $\mathbf{2 0 0 5}$ & $\mathbf{2 0 0 6}$ & $\mathbf{2 0 0 7}$ & $\mathbf{2 0 0 8}$ & $\mathbf{2 0 0 9}$ & $\mathbf{2 0 1 0 /}$ & $\mathbf{2 0 1 1 /}$ & $\mathbf{2 0 1 2 /}$ \\
$\mathbf{2 0 1 1}$ & $\mathbf{2 0 1 3 /}$ & $\mathbf{2 0 1 3}$ & $\mathbf{2 0 1 4}$ \\
\hline Bulgaria & 0 & 0 & 0 & 508 & 604 & 941 & 3021 & 4656 & 0 & 0 & 0 & 0 & 0 & 0 \\
\hline Colombia & 0 & 149 & 105 & 105 & 82 & 8 & 22 & 11 & 0 & 0 & 0 & 0 & 0 & 0 \\
\hline Ecuador & 0 & 0 & 8 & 8 & 64 & 26 & 12 & 14 & 7 & 0 & 0 & 0 & 0 & 0 \\
\hline Filipinas & 0 & 0 & 0 & 0 & 0 & 0 & 0 & 270 & 0 & 0 & 0 & 0 & 0 & 0 \\
\hline Marruecos & 198 & 336 & 95 & 620 & 1.094 & 2.330 & 5.277 & 13.600 & 14.190 & 5.450 & 5.300 & 2.409 & 2.185 & 2.000 \\
\hline Polonia & 540 & 4.954 & 7.535 & 8.506 & 7.361 & 9.796 & 0 & 0 & 0 & 0 & 0 & 0 & 0 & 0 \\
\hline Rumania & 0 & 970 & 4.178 & 10.589 & 13.186 & 19.153 & 20.710 & 20.634 & 0 & 0 & 0 & 0 & 0 & 0 \\
\hline Senegal & 0 & 0 & 0 & 0 & 0 & 0 & 0 & 749 & 40 & 0 & 0 & 0 & 0 & 0 \\
\hline Ucrania & 0 & 0 & 0 & 0 & 0 & 0 & 0 & 557 & 130 & 0 & 0 & 0 & 0 & 0 \\
\hline Total & $\mathbf{7 3 8}$ & $\mathbf{6 . 4 0 9}$ & $\mathbf{1 . 2 0 0}$ & $\mathbf{2 0 . 3 3 6}$ & $\mathbf{2 2 . 3 9 1}$ & $\mathbf{3 2 . 2 5 4}$ & $\mathbf{2 9 . 0 4 2}$ & $\mathbf{4 0 . 4 9 1}$ & $\mathbf{1 4 . 3 6 7}$ & $\mathbf{5 . 4 5 0}$ & $\mathbf{5 . 3 0 0}$ & $\mathbf{2 . 4 0 9}$ & $\mathbf{2 . 1 8 0}$ & $\mathbf{2 . 0 0 0}$ \\
\hline
\end{tabular}

* Son datos del cupo de reserva aprobado para estas campañas, el máximo que se autoriza a contratar, no las contrataciones efectivas. Fuente: Subdelegación del Gobierno en la provincia de Huelva, publicado en Gordo Márquez (2014: 178). Elaboración propia.

Tabla 2. Evolución de la contratación en origen en la provincia de Huelva.

\begin{tabular}{|c|c|c|}
\hline Año & Número de autorizaciones & \% periodo \\
\hline $\mathbf{2 0 0 8}$ & $\mathbf{4 2 . 7 1 9}$ & $\mathbf{2 8 , 7 9}$ \\
\hline 2009 & 3.411 & 2,30 \\
\hline 2010 & 11.983 & 8,07 \\
\hline 2011 & 14.618 & 9,85 \\
\hline 2012 & 6.655 & 4,48 \\
\hline 2013 & 2.963 & 2,00 \\
\hline 2014 & 2.834 & 1,91 \\
\hline 2015 & 2.767 & 1,86 \\
\hline 2016 & 5.562 & 3,75 \\
\hline 2017 & 17.537 & 11,82 \\
\hline 2018 & 18.179 & 12,25 \\
\hline $\mathbf{2 0 1 9}$ & $\mathbf{1 9 . 9 7 9}$ & $\mathbf{1 2 , 9 2}$ \\
\hline
\end{tabular}

Fuente: Ministerio de Trabajo, Migraciones y Seguridad Social, Portal de inmigración. Elaboración propia.

cia de la adhesión a la Unión Europea se comenzó a reducir drásticamente el número de contrataciones laborales, ya que se había marcado una moratoria en la que se limitaba la plena circulación laboral.

Sin duda, la actual problemática de las temporeras en los campos de Huelva desvirtúa lo establecido en el citado Acuerdo. Respecto de la importancia del trabajo realizado por estas mujeres, conviene recordar las palabras de la Ministra de Trabajo, Migraciones y Seguridad social, Magdalena Valerio: "al igual que en años anteriores, la campaña agrícola de temporada onubense es la más importante de nuestro país en términos de demanda de 
contratación colectiva en origen y se cubre con trabajadoras procedentes de Marruecos. En la campaña de este año se autoriza la cifra toral de 19.179 trabajadores, mil más que el año 2018 "23.

La preferencia por parte del empresariado onubense por trabajadoras marroquíes frente a mano de obra masculina, se basa en estereotipos meramente sexistas. A juicio de dicho empresariado, ellas "dan menos problemas", "son más trabajadoras" y "tienen más posibilidades de retorno" -en especial, si tienen cargas familiares- que sus homólogos varones, al tiempo que se las identifica con actitudes que consideran ventajosas para el trabajo, como que "no salen, no beben, no son problemáticas, etc." También se les atribuyen capacidades consideradas esencialmente femeninas como la "delicadeza" o la "sensibilidad" en las manos, que las hacen más válidas para la manipulación de los frutos rojos. Dicho empresariado atribuye estereotipos opuestos a los temporeros marroquíes, relacionados con comportamientos conflictivos o irresponsables: "salen, beben, arman bronca, faltan al trabajo" y "abandonan la campaña antes de su fin"24. En la misma línea, el empresariado considera que las mujeres marroquíes tienen un carácter ahorrativo, conservador y sumiso y que, por ello, son el perfil ideal de trabajadora.

La migración femenina responde muchas veces a la falta de oportunidades laborales en el país de origen, a lo que hay que sumar que la toma de decisión suele estar condicionada por la familia ${ }^{25}$.

\section{Condiciones de vida y trabajo en los campos de Huelva}

Las condiciones de vida y de trabajo de las trabajadoras marroquíes en los campos de la fresa en Huelva presentan enormes deficiencias; y es que, la puesta en relación del marco jurídico laboral español con el marroquí acaba propiciando la vulneración de los derechos laborales de estas trabajadoras, y abocándolas a situaciones de precariedad laboral extrema.

El Acuerdo bilateral celebrado entre España y Marruecos tendría por finalidad última "poner en marcha un programa con el objetivo de mejorar las condiciones de trabajo y el respeto de los derechos socio-económicos de estas mujeres" ${ }^{26}$. Sin embargo, dicho objetivo está muy lejos de alcanzarse, suscitando interrogantes tanto en el régimen de

\footnotetext{
${ }^{23}$ Asociación española de ciencia regional. (2019). Nuevo ciclo en España para la gestión colectiva de las contrataciones en origen. Recuperado de https://aecr.org/es/nuevo-ciclo-en-espana-para-la-gestion-colectiva-de-las-contrataciones-en-origen/ (En línea).

${ }^{24}$ Moreno Nieto. J, (2009). Los contratos en origen de temporada: mujeres marroquíes en la agricultura onubense. Revista de Estudios Internacionales Mediterráneos -REIM - № 7- (enero-mayo 2009) ISSN: 1887-4460.

${ }^{25}$ Asociación Pro Derechos Humanos de Andalucía, Asociación de Nuevos Ciudadanos por la Interculuralidad (ASNUCI), Cáritas, Cooperación y Desarrollo con el Norte de África (CODENAF), Fundación Europea para la Cooperación Norte-Sur (FECONS), Huelva Acoge y Mujeres en Zona de Conflicto (MZC) (2018). Realidad de los asentamientos en la provincia de Huelva. Recuperado de https://www.apdha.org/media/Informe-Asentamientos-Mesa Integracion-Huelva. pdf (En línea).

${ }^{26}$ Ofxam Intermón. (2009). Trabajadoras de la fresa en Marruecos: un camino hacia la dignidad. Recuperado de https://www.oxfamintermon.org/es/programas-de-desarrollo/proyectos/proteccion-social-de-trabajadoras-de-fresa-en-marruecos (En línea).
} 
selección de las trabajadoras como las condiciones de vida y de trabajo efectivamente disfrutadas por las mismas.

Por lo pronto, las mujeres son seleccionadas en base a criterios claramente discriminatorios, pues se exige que las candidatas sean mujeres, que estén casadas (con autorización expresa del cónyuge), viudas o divorciadas (con la aportación de acta de divorcio o certificado de viudedad), vivan en zonas rurales con experiencia en el sector de la agricultura ${ }^{27}$, tengan hijos/as -para garantizar su arraigo familiar y su regreso al país una vez terminada la temporada-, y no cuenten con más de 45 años para que puedan responder a las exigencias físicas requeridas para el cultivo y la recolección de la fresa ${ }^{28}$. Comisiones Obreras de Andalucía ha exhortado al Ministerio de Empleo a que imponga criterios no discriminatorios similares a los utilizados para la contratación de personas trabajadoras en España ${ }^{29}$ : "El Ministerio tiene que exigir que estos sean aplicados por el Organismo de la Administración marroquí que debe realizar la selección, a lo que hay que añadir que este proceso debe ser absolutamente transparente y respetuoso con los derechos de las personas"30.

Sin duda, nos encontramos ante un supuesto de vulneración de derechos fundamentales, que atenta contra la dignidad de estas mujeres ${ }^{31}$ al ser tratadas como mera mercancía. Es imprescindible que el Ministerio de Trabajo, Migraciones y Seguridad Social, junto a la cooperación de la Administración marroquí y las organizaciones de la patronal, modifiquen urgentemente los criterios de selección para hacerlos similares a los aplicables a las personas trabajadoras españolas, y que evite que la selección de estas mujeres se siga realizando sobre la base de estereotipos sexistas, y bajo condicionamientos que las colocan en situación de extrema dependencia y vulnerabilidad.

A este respecto, CCOO de Huelva sostiene que los requisitos exigidos a las temporeras marroquíes son discriminatorios porque no se valoran prioritariamente los aspectos profesionales, sino circunstancias de carácter personal ligadas a conceptos machistas como la edad, el hecho de que tengan que estar casadas o viudas y con cargas familiares para asegurarse el retorno. Para CCOO los criterios de selección deben ser profesionales, y a igualdad de condiciones, establecer criterios socioeconómicos ${ }^{32}$.

A lo anterior cabe añadir algo tan obvio como que son contrarias al Ordenamiento Jurídico español, por resultar discriminatorias las ofertas de empleo que establezcan una

\footnotetext{
${ }^{27}$ El País. (2018). Fresas sin explotación ni acoso sexual. Recuperado de https://elpais.com/elpais/2018/06/07/ mujeres/1528396330_755399.html (En línea).

${ }^{28} 20$ minutos. (2018). CCOO critica los criterios "retrógrados y machistas" para la contratación en la campaña fresera. Recuperado de https://www.20minutos.es/noticia/3245587/0/ccoo-critica-criterios-retrogrados-machistas-paracontratacion-campana-fresera/ (En línea). Criterios de contratación exigidos por el Ministerio de Empleo de España, en colaboración con el Organismo de Administración Pública y de las Agencias de Colocación del Reino Marruecos.

${ }^{29}$ Sobre la materia véase, Echajri Amhaouch, I. (2019), La discriminación de las mujeres inmigrantes en España, pág. 141, Ediciones Laborum - Plataforma ACCIÓN SOCIAL.

${ }^{30}$ Nueva Tribuna. (2018). Los criterios de contratación de mujeres marroquíes para la campaña de la fresa son "machistas y retrógrados". Recuperado de http://www.nuevatribuna.es/articulo/economia-social/andalucia-criterios-contratacion-campana-fresa-son-retrogrados-machistas (En línea).

${ }^{31}$ Art. 10.1 CE: La dignidad de la persona, los derechos inviolables que le son inherentes, el libre desarrollo de la personalidad, el respeto a la ley y a los derechos de los demás son fundamento del orden político y de la paz social.

${ }^{32}$ El mar de Onuba. (2019). Una ONG marroquí denuncia 'condiciones discriminatorias en la selección de trabajadores' para la recogida de fresas en Huelva. Recuperado de http://revista.lamardeonuba.es/una-ong-marroqui-denuncia-condiciones-discriminatorias-en-la-seleccion-de-trabajadores-para-la-recogida-de-fresas-en-huelva/ (En línea).
} 
preferencia por personas trabajadoras de un determinado sexo (arts. 14 CE, 17.1 ET, y 5 LOI). A este respecto, específicamente, el art. 35.2 del Real Decreto Legislativo 3/2015, de 23 de octubre, por el que se aprueba el texto refundido de la Ley de Empleo (LE), señala que "se considerarán discriminatorias las ofertas referidas a uno de los sexos, salvo que se trate de un requisito profesional esencial y determinante de la actividad a desarrollar". Ser mujer casada, viuda o divorciada, con hijos/as, y menor de 45 años no constituye "un requisito profesional esencial y determinante de la actividad" de recolección de fresa, sino exigencias discriminatorias basadas en el sexo, el estado civil y la edad, asentadas en estereotipos sexistas, que sitúan a estas mujeres marroquíes en situación de extrema vulnerabilidad en el desarrollo de su actividad laboral, y que, como es lógico, carecen de amparo en el ordenamiento jurídico español. El Ministerio de Trabajo español ha de velar por que la Administración marroquí no aplique criterios de selección discriminatorios incompatibles con el Derecho español y el marco jurídico de la Unión Europea.

Una vez seleccionadas, contratadas y desplazadas a los campos de Huelva, muchas de estas mujeres sufren durísimas condiciones de vida y trabajo, agravadas todavía más, si cabe, por una falta de una protección adecuada en materia de seguridad y salud ${ }^{33}$. Así lo reflejan algunas sentencias judiciales, noticias de prensa, y el testimonio de las víctimas.

La Sentencia de la Audiencia Provincial de Huelva, de 24 de abril de $2014^{34}$, fue dictada tras la denuncia de varias trabajadoras marroquíes, de entre 18 y 30 años, que vivían temporalmente en medio del campo en casas en mal estado, a cinco patronos españoles por abuso sexual, del que se derivaron graves secuelas físicas y psíquicas. El órgano judicial consideró probada la existencia de los abusos, y que las trabajadoras efectuaban jornadas de diez horas, desempeñando las tareas propias de la explotación agrícola, no respetándose el tiempo mínimo para la comida o sin tener días libres ni paga por horas extraordinarias; no les permitían beber agua ni abandonar el puesto de trabajo, y las insultaban de forma constante: "Putas, os vamos a mandar a Marruecos, cojones, que en vuestro país estáis muertas de hambre", "hijas de puta, tontas, inútiles". Las sometían en la jornada laboral a una vigilancia estrecha hasta el punto de obligarlas a hacer sus necesidades en el mismo campo, impidiendo que se relacionasen con trabajadores y trabajadoras de otras fincas o que abandonaran la misma si no eran acompañadas, haciendo uso de la fuerza física en alguna ocasión, y solicitando, en otras, favores sexuales para garantizar la continuidad del trabajo ${ }^{35}$.

Otras denuncias, sin embargo, no tuvieron, al menos inicialmente, el mismo resultado. Cabe señalar un sorprendente caso de sobreseimiento provisional de la causa por acoso sexual, sin que el Juez escuchara el relato de las trabajadoras temporeras ni admitiera los medios de prueba (testimonios y material audiovisual) aportados por la repre-

\footnotetext{
${ }^{33}$ Como afirma Molina González-Pumariga, R. (2004). La protección jurídica de la mujer trabajadora, Consejo Económico y Social, Madrid, pág. 130. “El trabajo femenino permanece invisible, centrándose los planes de prevención en riesgos que pueden ocasionar accidentes de trabajo, pero olvidando generalmente el resto, lo que produce una situación de discriminación en materia de salud laboral del colectivo femenino".

${ }^{34}$ Sección 3ạ , Núm. Recurso 143/2014. Número CENDOJ: 21041370032014100264.

${ }^{35}$ El País. (2018). Fresas sin explotación ni acoso sexual. Recuperado de https://elpais.com/elpais/2018/06/07/ mujeres/1528396330_755399.html (En línea).
} 
sentación legal de las trabajadoras, dando por buenas las explicaciones del empresario. Sin embargo, finalmente, la Audiencia Provincial de Huelva, mediante auto de 13 de mayo de 2019, ha levantado el sobreseimiento provisional de la causa, ordenando al Juez a reabrir el caso en los siguientes términos: "procede recibir las declaraciones, practicándose igualmente cualquier otra diligencia que de las mismas se derive o se repute necesaria, y luego adoptar la decisión oportuna en orden a la continuación o sobreseimiento de las actuaciones"36. Estas mujeres denuncian amenazas y vejaciones del siguiente tenor: "O te dejas, o te quedas sin trabajo". "O eres buena conmigo, o no vuelves el año que viene". "Si no te portas bien como yo quiero, te prohíbo ir al baño y beber agua a 40 grados bajo el sol". "Hazme caso o te cuento menos cajas"37.

Tras visitar los campos de Huelva, en 2010, la eurodiputada por el partido Los Verdes, Hélène Flautre, calificó como trágica la situación atravesada por estas mujeres, afectadas por unas condiciones de vida inadecuadas, sin agua potable, hacinamiento (de cuatro a seis mujeres por habitación distribuidas en literas) y un trato discriminatorio y sexis$\operatorname{ta}^{38}$. En la misma línea, la revista alemana Correctiv denuncia que se producen, además de violaciones y abusos sexuales, un inusitado número de abortos en los campos de Huelva. En la revista se cita a Josefa Mora Gómez, trabajadora social en el Centro de Salud Pública local y que "debe aprobar cualquier solicitud de aborto que se realice allí", quien manifiesta que se practicaron 185 abortos en Palos y la ciudad vecina de Moguer en 2016, el 90\% de los cuales fueron solicitados por trabajadoras temporales procedentes de Marruecos, Rumania y Bulgaria, todos ellos a raíz de violaciones ${ }^{39}$.

Estos son algunos de los tristes ejemplos que muestran las precarias condiciones de vida $^{40}$ y de trabajo, y las situaciones de violencia que sufren muchas de las trabajadoras magrebíes en Huelva, con cuyo denodado esfuerzo el negocio del cultivo y la exportación de la fresa y otros productos agrícolas alcanzan excelentes resultados todos los años. Como se ha señalado, muchas de estas trabajadoras se ven en la necesidad de soportar indignas condiciones de vida y trabajo, debido a que tienen cargas familiares y necesitan los ingresos económicos obtenidos para mantener a sus familias; pero otras deciden fugarse del infierno sufrido. Este es el caso Milouda, una ex-trabajadora de la fresa que pasó

${ }^{36}$ El Mar de Onuba. (2019). La Audiencia Provincial tumba el sobreseimiento y ordena al juez Serrano de La Palma del Condado escuchar el testimonio de las "Temporeras contra la esclavitud". Recuperado de http://revista.lamardeonuba. es/la-audiencia-provincial-tumba-el-sobreseimiento-y-vuelva-a-ordenar-al-juez-serrano-de-la-palma-del-condadoescuchar-por-videoconferencia-el-testimonio-de-las-temporeras-contra-la-esclavitud/ (En línea).

${ }^{37}$ Andreu, J., y Jiménez, L. (2010). Víctimas del oro rojo. Recuperado de https://elpais.com/diario/2010/06/13/ domingo/1276401156_850215.html (En línea).

${ }^{38}$ Andreu, J., y Jiménez, L. (2010). Víctimas del oro rojo. Recuperado de https://elpais.com/diario/2010/06/13/ domingo/1276401156_850215.html

${ }^{39}$ Público. (2018). Una revista alemana denuncia violaciones a mujeres y abortos en los campos de fresa de Huelva. Recuperado de http://www.publico.es/sociedad/abuso-trabajadoras-migrantes-revista-alemana-denuncia-violacionesmujeres-abortos-campos-fresa-huelva.html (En línea).

${ }^{40}$ No debe pasarse por lo alto que el acceso a la vivienda no es un lujo sino más bien un derecho básico y una necesidad de todo ser humano. Así queda reflejado en el art. 25.1 de la Declaración Universal de los Derechos Humanos: "toda persona tiene derecho a un nivel de vida adecuado que le asegure, así como a su familia, la salud y el bienestar, y en especial la alimentación, el vestido, la vivienda, la asistencia médica y los servicios sociales necesarios; tiene asimismo derecho a los seguros en caso de desempleo, enfermedad, invalidez, viudez, vejez u otros casos de pérdida de sus medios de subsistencia por circunstancias independientes de su voluntad". 
a ser trabajadora en situación irregular, y ahora vive de la prostitución; o el de Shadia, otra ex-trabajadora de 25 años, que llegó a los campos de la fresa dejando a su hijo de pocos meses, y quien ante el acoso de su jefe para que mantuviera relaciones sexuales con él, acabó abandonando el trabajo a las seis semanas: "Le gustaban las chicas que venían de Marruecos". "Cuando una no quería estar con él, la despedía”. "Muchas decían que sí, pero yo no quería eso, así que me fui. Desde entonces he tenido muchos problemas por los papeles, pero lo prefiero", afirma Shadia ${ }^{41}$.

Durante la redacción del presente artículo, tuve la oportunidad de conocer a Najat ${ }^{42}$, de 35 años de edad, divorciada y con hijos menores a cargo, procedente de Beni Mellal, en el sur de Marruecos. Hace varios años vino a los campos de Huelva como temporera. Afirma que las condiciones laborales eran muy precarias, las condiciones de vivienda pésimas, y los piropos sexistas constantes. Tras permanecer unos meses trabajando y al observar la conducta de los empresarios decidió huir de ese lugar y residir en otra provincia, lejos de los campos de Huelva, donde la misma afirma que vivió una experiencia penosa. Actualmente se encuentra en situación ilegal, y trabaja sin alta en la Seguridad Social al carecer de autorización por residencia y/o trabajo. Señala que, si no se produjeran abusos sexuales en las fincas, y que si el trato hubiera sido adecuado habría permanecido trabajando pese a las malas condiciones laborales y de vivienda: "Éramos distribuidas como animales en granjas". "Nos tratan como mercancías". "Cuando reclamo sobre mis derechos, el empresario me dice aquí por lo menos vives mejor que en Marruecos; los $30 €$ que ganas al día hacen fortuna en tu país, así que trabaja y cállate". "Con frecuencia nos escupían mientras trabajamos", afirma Najat.

Las trabajadoras de la fresa esperan un futuro mejor en España, y un salario digno para mantener a sus familiares; pero, lejos de alcanzar su propósito, como se ha descrito, con demasiada frecuencia se convierten en víctimas de acoso, agresiones sexuales y trata.

\section{5. Órdenes ministeriales sobre la gestión colectiva de contratación en origen}

5.1. Orden TMS/1426/2018, de 26 de diciembre, por la que se regula la gestión colectiva de contrataciones en origen para 2019

El 31 de diciembre de 2018 se publicó en el BOE la Orden TMS/1426/2018, de 26 de diciembre, por la que se regula la gestión colectiva de contrataciones en origen para 2019. Hasta ese momento, se había venido prorrogando la Orden ESS/1/2012, de 5 de enero, por la que se regulaba la gestión colectiva de contrataciones en origen para el año 2012. La nueva orden ministerial tiene un doble objetivo: por una parte, introducir mejoras de gestión del procedimiento de contratación de temporada y, por otra, promover

\footnotetext{
${ }^{41}$ Andreu, J., y Jiménez, L. (2010). Víctimas del oro rojo. Recuperado de https://elpais.com/diario/2010/06/13/ domingo/1276401156_850215.html (En línea).

${ }^{42}$ El nombre de la entrevista ha sido sustituido por otro nombre ficticio con la finalidad de velar por el anonimato de esta temporera.
} 
y fortalecer la contratación estable, segura, ordenada y regular ${ }^{43}$, lejos de unas condiciones de trabajo precarias que se han venido denunciando en últimos siete años. La Orden TMS/1426/2018 viene motivada por cuatro factores de especial transcendencia ${ }^{44}$ : el seguimiento de los resultados de la Cumbre de la Valeta sobre Migración de $2015^{45}$, la asunción por España del Pacto Global de Migraciones ${ }^{46}$, la consolidación de una práctica de migración circular y, de manera particular, la contratación en origen de ciudadanos/as marroquíes para campañas agrícolas, y el análisis del mercado de trabajo para aquellos sectores de trabajo no cubiertos con la mano de obra nacional.

La Orden TMS/1426/2018 introduce varias mejoras en comparación con la anterior normativa, entre ellas: el incremento en las actuaciones de Inspección de Trabajo y de Seguridad Social con la finalidad de controlar que se cumple correctamente la normativa laboral y de Seguridad Social. Las mejoras incorporadas intentan dar respuesta a las denuncias producidas en los últimos siete años. Con la entrada en vigor de la Orden TMS/1426/2018, en la que se introducen mejoras significativas en comparación con la normativa anterior -que incluyen controles preventivos y actuaciones constantes de la Inspección de Trabajo para velar por el cumplimiento de la normativa en materia de Derecho del Trabajo y de la Seguridad acciones de acompañamiento en las áreas sociales para una adecuada integración, intervención de servicios sociales, etc. Se intentan evitar los abusos sexuales, las condiciones de trabajo precarias y la irregularidad administrativa, que sufren las trabajadoras inmigrantes, como es el caso de las temporeras en los campos de Huelva.

5.2. Orden TMS/1277/2019, de 23 de diciembre, por la que se regula la gestión colectiva de contrataciones en origen para 2020

El pasado 23 de diciembre de 2019 entro en vigor la nueva Orden Ministerial que regula la contratación en origen y el visado de búsqueda de empleo para hijos o nietos de español de origen. En contraposición con la Orden del año 2018, la presente intenta dar respuesta a la controversia sobre las condiciones de vida y trabajo que sufren las temporeras en los campos de Huelva, que hasta el momento son objeto de múltiples denuncias.

\footnotetext{
${ }^{43}$ El Gobierno aprueba la orden para la gestión colectiva de contratación en origen de 2019. Recuperado de http:// prensa.empleo.gob.es/WebPrensa/noticias/inmigracionemigracion/detalle/3441 (En línea).

${ }^{44}$ Murciano Alvárez, G. (2019). Nueva regulación en la contratación colectiva de extranjeros en origen en 2019. Recuperado de https://blog.sepin.es/2019/02/contratacion-colectiva-extranjeros/ (En línea).

${ }^{45}$ La Cumbre de la Valeta sobre Migración es un acuerdo establecido entre los respectivos Gobiernos de los Estados miembros de la UE y los Gobiernos africanos que tiene por finalidad reforzar la cooperación y abordar la problemática que radica en la inmigración clandestina. Con este acuerdo se intenta establecer una responsabilidad compartida entre ambos Gobiernos con la finalidad de proponer soluciones óptimas relacionadas con la inmigración. Recuperado de https://www.consilium.europa.eu/es/meetings/international-summit/2015/11/11-12/ (En línea).

${ }^{46}$ El Pacto Global de Migraciones tiene por finalidad velar por una inmigración regular, segura y ordenada. Dicho pacto se celebró el pasado diciembre de 2018 antes de la entrada en vigor de la Orden TMS/1426/2018. Dicho pacto tiene establecido un conjunto de objetivos, tales como: la implementación de los acuerdos internacionales, el compromiso entre Estados, mejorar la gobernanza mundial en la persecución de un mundo donde las personas se mueven por su elección genuina y no por necesidad, etc., pero lo más transcendental es velar por la protección de las mujeres trabajadoras en los campos de España. Recuperado de http://www.mitramiss.gob.es/cartaespana/es/noticias/Noticia_0461.htm (En línea).
} 
Esta Orden aprueba una previsión de las contrataciones de temporada, y amplía el proyecto piloto de visados para búsqueda de empleo para hijos/as y nietos/as con la intención de que sea desarrollado en distintos países iberoamericanos ${ }^{47}$, entre los que se encuentra Argentina. En la misma línea, y con el objetivo de alcanzar una migración ordenada, regular y segura, la Secretaría de Estado de Migraciones ha elegido a Argentina como país piloto para este proyecto. En el año 2018 se formalizó cerca de 3.064 solicitudes, se seleccionaron 1.038 personas y de estas personas se han concedido alrededor de 700 visados de búsqueda de empleo para hijos/as y nietos/as de españoles. Hay que destacar pues, que las personas seleccionadas disponen de una titulación y/o experiencia laboral necesarias para trabajar en sectores que requieran media y alta cualificación profesional, especialmente los puestos de trabajo relacionados con la tecnología, la informática, la investigación, el marketing y las finanzas ${ }^{48}$.

En la campaña de este año se autoriza una cifra total de 20.195 trabajadores/as; de la cual 13.695 son repetidores de campañas anteriores, favoreciendo de esta manera una migración circular, segura y ordenada, y 6.500 provienen de una selección realizada en Marruecos ${ }^{49}$.

En este sentido, la Orden de 2019 preveía un cupo de hasta 1.500 visados destinados a la búsqueda de empleo a hijos o nietos de españoles, mientras que para el año 2020 este cupo es aumentado hasta 5.000 visados $^{50}$.

Entre las mejoras introducidas son muy similares a las del 2019, entre las que podemos citar las siguientes ${ }^{51}$ : adelantar la campaña administrativa, mejorar los procesos de coordinación y planificación entre las administraciones implicadas y los agentes sociales que intervienen, velar por la seguridad e higiene e intensificar el cumplimiento de la normativa laboral y de seguridad social aplicable, entre muchos otros.

Ello, no obstante, la Secretaría de Estado de Migraciones publicó en su Instrucción 2/2020 sobre la suspensión de los procedimientos enmarcados en la Orden TMS/1277/2019 como consecuencia alcance del Real Decreto 463/2020, de 14 de marzo, por el que se declara el estado de alarma para la gestión de la situación de crisis sanitaria ocasionada por el COVID-1952.

\footnotetext{
${ }^{47}$ Orden TMS/1277/2019, de 23 de diciembre, por la que se regula la gestión colectiva de contrataciones en origen para 2020. Recuperado de https://www.boe.es/diario_boe/txt.php?id=BOE-A-2019-18753. (En línea)

${ }^{48}$ Europapress (2019). El Gobierno aprueba la orden para la gestión colectiva de contratación en origen de 2020. Recuperado de https://www.europapress.es/economia/laboral-00346/noticia-gobierno-aprueba-orden-gestion-colectiva-contratacion-origen-2020-20191231103329.html. (En línea)

${ }^{49}$ Noticias bancarias (2020). Aprueban orden para la gestión colectiva de contratación en origen de 2020. Recuperado de https://noticiasbancarias.com/economia-y-finanzas/03/01/2020/aprueban-orden-para-la-gestion-colectiva-decontratacion-en-origen-de-2020/201335.html. (En línea)

${ }^{50}$ Art. 20 de Orden TMS/1277/2019, de 23 de diciembre, por la que se regula la gestión colectiva de contrataciones en origen para 2020.

${ }^{51}$ AgrodiarioHuelva (2020). El Gobierno autoriza la contratación en origen de 20.195 trabajadores para la campaña agrícola de 2020 en Huelva. Recuperado de http://agrodiariohuelva.es/2020/01/03/el-gobierno-autoriza-la-contratacion-en-origen-de-20-195-trabajadores-para-la-campana-agricola-de-2020-en-huelva/. (En línea)

${ }^{52}$ Instrucción 2/2020 de la Dirección General de Migraciones sobre la suspensión de los procedimientos enmarcados en la Orden TMS/1277/2019, de 23 de diciembre, por la que se regula la gestión colectiva de contrataciones en origen para 2020. Recuperado de http://extranjeros.inclusion.gob.es/es/normativa/nacional/instrucciones_sgie/ documentos/2020/INSTRUCCION_2-2020_SUSPENSION_ORDEN_GECCO.pdf. (En línea)
} 


\section{Trabajo, género y cultura}

Tradicionalmente, el acceso de la mujer marroquí rural al mundo laboral fuera de Marruecos le reporta una "mala reputación", al considerarse que tal actividad afecta a la honra del entorno personal-familiar. Hasta nuestros días, la principal labor de la mujer magrebí rural ha sido el cuidado del hogar familiar. Algunas mujeres realizan ciertas actividades en la agricultura o la ganadería, en condiciones laborales precarias y con bajos salarios $^{53}$. En las zonas rurales de Marruecos son características las familias muy numerosas, de 8 a 13 miembros. El salario del hombre, principal o único sostenedor económico de la familia, suele situarse entre los 15 y los 20 euros diarios, claramente insuficientes para hacer frente a los gastos familiares.

La contratación en origen se ha considerado como una vía de escape de la pobreza por parte de estas mujeres, una ayuda para el sostenimiento de la familia que queda en el país de origen, y la apertura a unas mejores condiciones de vida. Retomando el tema de los 185 abortos practicados en Palos y la ciudad vecina de Moguer en 2016 (el 90\% de los cuales fueron solicitados por trabajadoras temporales extranjeras, a raíz de violaciones sufridas por las mismas), cabe señalar, respecto de las mujeres marroquíes víctimas de violaciones y trata, que estas suelen ocultar la dura experiencia vivida en España por el temor fundado a ser consideradas una "deshonra" para la familia; asimismo, guardan silencio por miedo a perder sus trabajos o no repetir la campaña los siguientes años ${ }^{54}$. De otro lado, su acceso al sistema judicial resulta casi imposible porque, al no dominar el idioma, les resulta extremadamente difícil hacer valer sus derechos ante los tribunales ${ }^{55}$.

\section{Conclusiones}

La elaboración del presente artículo nos ha permitido conocer la verdadera realidad de las trabajadoras magrebíes en España. Estas mujeres emigran con la aspiración de disfrutar de unas condiciones de vida y de trabajo cuyo país de origen no les puede ofrecer. Sin embargo, determinado empresariado se aprovecha de su desfavorable situación -agravada por la exigencia de determinados requisitos personales y familiares en el proceso de selección-, para ofrecerles puestos de trabajo en condiciones laborales inadecuadas y, en ocasiones, deplorables y cercanas a la trata con fines de explotación laboral y sexual.

Las demandas ante los Juzgados de lo Social son muy escasas, pues estas mujeres, todas ellas con menores a su cargo en su país de origen, temen que les sea denegada la autorización de residencia o ser expatriadas a su país de origen, con la imposibilidad de

\footnotetext{
${ }^{53}$ Actualmente, el salario mínimo profesional es de 4.000 dírhams, lo que equivale a 366 euros mensuales.

${ }^{54}$ ABDdesevilla. (2018). Supuestos abusos en los campos de Huelva: "Están mintiendo porque les han prometido papeles para quedarse en España". Recuperado de https://sevilla.abc.es/andalucia/sevi-supuestos-abusos-campos-huelvaestan-mintiendo-porque-prometido-papeles-para-quedarse-espana-201806080729_noticia.html (En línea).

${ }^{55}$ Público. (2018). Una revista alemana denuncia violaciones a mujeres y abortos en los campos de fresa de Huelva. Recuperado de http://www.publico.es/sociedad/abuso-trabajadoras-migrantes-revista-alemana-denuncia-violacionesmujeres-abortos-campos-fresa-huelva.html (En línea).
} 
tener trabajo en las siguientes campañas. Dicho temor se atenuaría si estas mujeres contaran con el apoyo y la protección adecuada en materia normativa, sindical, policial, judicial y de la Inspección de Trabajo.

La situación descrita impide que las personas inmigrantes disfruten de su derecho humano a tener una vida digna, en las mismas condiciones que las nacionales, trasformando el deseo legítimo de aquellas de vivir en un lugar que les ofrezca un futuro estable en una presión por parte del mercado de trabajo. La sociedad española tiene que ser consciente de que las personas inmigrantes no se desplazan a España a "quitar el trabajo a las personas nacionales", sino más bien a ocupar puestos rechazados por la mano de obra interna, y que, sin embargo, es necesario cubrir para el garantizar el correcto funcionamiento de la economía. Sin embargo, erróneamente, la sociedad percibe la inmigración como un peligro para el desarrollo y el progreso, siendo todo lo contrario, la inmigración es un factor de crecimiento e innovación.

Las condiciones laborales y vitales de las mujeres que trabajan en los campos de Huelva son durísimas. Para poner fin a esta situación, a veces cercana a la explotación, en la línea ya iniciada por la Orden TMS/1477/2019, es necesario reforzar la labor de la Inspección de trabajo y de la Seguridad social y de los servicios sociales. Y, asimismo, es preciso poner los medios para evitar que la selección de estas mujeres en Marruecos se siga realizando sobre la base de estereotipos sexistas y, en cuanto tales, discriminatorios, y bajo condicionamientos que las colocan en situación de extrema dependencia y vulnerabilidad.

Resulta relativamente fácil llegar a la conclusión de que la contratación en origen puede ser considerada como una práctica de pleno derecho en codesarrollo. Existen pues, varias razones que lo justifican ${ }^{56}$ :

1. La contratación en origen es el instrumento contractual que mejor se aproxima a las expectativas de control y gestión de flujos migratorios, pues atiende tanto a las necesidades de España como de los países donde se contrata esta mano de obra; si bien es verdad que los cupos siempre quedan supeditados a la situación nacional de empleo existente en España.

2. El retorno del contingente contratado bajo esta fórmula se asegura, al menos en teoría, desde la firma misma del contrato de trabajo, ya que es una condición para acogerse a este tipo de contratos.

3. Se promueve el carácter temporal de los flujos migratorios, pues los contractos en agricultura están ligados a las campañas agrícolas, que tienen una duración limitada coincidente con la finalización de las mismas.

4 El papel del inmigrante es clave en todo el proceso, pues se ve implicado directamente tanto en el desarrollo de la localidad hacia la que emigra temporalmente como de la que parte.

\footnotetext{
${ }^{56}$ Macías Llaga, I, Márquez Domínguez, J.A y Jurado Almonte J.M. (2016). La contratación en origen de temporeros marroquíes para los campos españoles como experiencia de codesarrollo. Recuperado de https://revistaseug.ugr.es/index.php/cuadgeo/article/view/3910/5149 (En línea).
} 


\section{Bibliografía}

20 minutos (2018). CCOO critica los criterios "retrógrados y machistas" para la contratación en la campaña fresera. Recuperado de https://www.20minutos.es/noticia/3245587/0/ccoo-critica-criterios-retrogrados-machistas-para-contratacioncampana-fresera/ (En línea).

$\mathrm{ABC}$ (2016). Explotación de inmigrantes en el campo: seis euros al día y heridas en las manos. Recuperado de http://www.abc.es/espana/comunidad-valenciana/abci-explotacion-inmigrantes-campo-seis-euros-y-heridas-manos-201612031200_noticia.html (En línea).

ABDDESEVILLA (2009). El Gobierno autoriza 19.000 temporeras marroquíes en Huelva. Recuperado de https://sevilla.abc.es/andalucia/huelva/sevi-gobierno-autoriza-19000temporeras-marroquies-huelva-201911020821_noticia.html (En línea).

ABDdESEVILla (2018). Supuestos abusos en los campos de Huelva: "Están mintiendo porque les han prometido papeles para quedarse en España". Recuperado de https://sevilla. abc.es/andalucia/sevi-supuestos-abusos-campos-huelva-estan-mintiendo-porqueprometido-papeles-para-quedarse-espana-201806080729_noticia.html (En línea).

AgrodiarioHuelva (2020). El Gobierno autoriza la contratación en origen de 20.195 trabajadores para la campaña agrícola de 2020 en Huelva. Recuperado de http://agrodiariohuelva.es/2020/01/03/el-gobierno-autoriza-la-contratacion-en-origen-de20-195-trabajadores-para-la-campana-agricola-de-2020-en-huelva/ (En línea).

ANDREU, J. y JimÉnEz, L (2010). Víctimas del oro rojo. Recuperado de https://elpais.com/ diario/2010/06/13/domingo/1276401156_850215.html (En línea).

Asociación EsPañola de Ciencia Regional. (2019). Nuevo ciclo en España para la gestión colectiva de las contrataciones en origen. Recuperado de https://aecr.org/es/ nuevo-ciclo-en-espana-para-la-gestion-colectiva-de-las-contrataciones-en-origen/ (En línea).

Asociación Pro Derechos Humanos de Andalucía, Asociación de Nuevos Ciudadanos POR LA INTERCULURALIDAD (ASNUCI), CÁRITAS, COOPERACIÓN Y DESARROLlO CON EL Norte de África (CODENAF), FundaCión Europea PARA la CoOperación NorteSur (FECONS), Huelva Acoge y Mujeres en Zona de Conflicto (MZC) (2018). Realidad de los asentamientos en la provincia de Huelva. Recuperado de https://www. apdha.org/media/Informe-Asentamientos-Mesa Integracion-Huelva.pdf (En línea).

Bajo Santos, N (2007). Conceptos y teorías sobre inmigración, Anuario Jurídico y Económico Escurialense, pág. 819. Recuperado de https://www.rcumariacristina.com/wpcontent/uploads/2010/12/V-NICOLAS-BAJO-SANTOS.pdf (En línea).

Cembrero, I (2018). España recibe ya más inmigrantes irregulares de Marruecos que Italia de Libia. Recuperado de https://www.elconfidencial.com/mundo/2018-06-25/ espana-recibe-ya-mas-inmigrantes-irregulares-de-marruecos-que-italia-de-libia_1583374/ (En línea).

Cope (2019). La contratación en origen es imprescindible para la campaña agrícola. Recuperado de https://www.cope.es/emisoras/andalucia/huelva-provincia/huelva/ 
noticias-agrarias/noticias/contratacion-origen-imprescindible-para-campanaagricola-20191108_546411 (En línea).

DIARIO DE BURGOS (2010). Los inmigrantes acaparan trabajos que no quieren hacer los españoles. Recuperado de http://www.diariodeburgos.es/noticia.cfm/Economia/20101101/ inmigrantes/acaparan/trabajos/no/quieren/hacer/espa\%C3\%B1oles/269FA2B1F3B6-16DA-A9E0DE8D5083454C (En línea).

ECHAJRI AMHAOUCH, I. (2019), La discriminación de las mujeres inmigrantes en España, pág. 141, Ediciones Laborum - Plataforma ACCIÓN SOCIAL.

El Mar de Onuba (2019). La Audiencia Provincial tumba el sobreseimiento y ordena al juez Serrano de La Palma del Condado escuchar el testimonio de las "Temporeras contra la esclavitud". Recuperado de http://revista.lamardeonuba.es/la-audiencia-provincial-tumba-el-sobreseimiento-y-vuelva-a-ordenar-al-juez-serrano-de-la-palma-delcondado-escuchar-por-videoconferencia-el-testimonio-de-las-temporeras-contrala-esclavitud/ (En línea).

El MAR DE ONUBA (2019). Una ONG marroquí denuncia 'condiciones discriminatorias en la selección de trabajadores' para la recogida de fresas en Huelva. Recuperado de http://revista.lamardeonuba.es/una-ong-marroqui-denuncia-condiciones-discriminatorias-en-la-seleccion-de-trabajadores-para-la-recogida-de-fresas-en-huelva/ (En línea).

EL PAís. (2018). Fresas sin explotación ni acoso sexual. Recuperado de https://elpais.com/ elpais/2018/06/07/mujeres/1528396330_755399.html (En línea).

EUROPAPRESS (2019). El Gobierno aprueba la orden para la gestión colectiva de contratación en origen de 2020. Recuperado de https://www.europapress.es/economia/ laboral-00346/noticia-gobierno-aprueba-orden-gestion-colectiva-contratacionorigen-2020-20191231103329.html. (En línea)

Instituto Nacional de Estadística (2019). Población extranjera por Nacionalidad, comunidades, Sexo y Año, 2009-2018. Recuperado de https://www.ine.es/jaxi/Datos. htm?path=/t20/e245/p08/10/\&file=02005.px (En línea).

LAVANGUARDIA(2018). Másde18.000temporerasmarroquíesviajanesteañoa Españaarecoger fresa. Recuperado de http://www.lavanguardia.com/vida/20180125/44280770931/ mas-de-18000-temporeras-marroquies-viajan-este-ano-a-espana-a-recoger-fresa. html (En línea).

LóPEz Pino, C.M. (2004). El mercado laboral de la población inmigrante en España, un estudio de caso, Gestión Humana, pág. 126. Recuperado de http://www.scielo.org.co/ pdf/inno/v14n23/v14n23a10.pdf (En línea).

Macías Llaga, I, Márquez Domínguez, J.A. y Jurado Almonte J.M. (2016). La contratación en origen de temporeros marroquíes para los campos españoles como experiencia de codesarrollo. Recuperado de https://revistaseug.ugr.es/index.php/cuadgeo/article/view/3910/5149 (En línea).

Made for minds. (2016). Entrada masiva de inmigrantes por el sur de España. Recuperado de https://www.dw.com/es/entrada-masiva-de-inmigrantes-por-el-sur-de-espa\%C3\% B1a/a-19210253 (En línea). 
Migración y DEREchos humanos: Mejora de la Gobernanza basada en los derechos humanos de la inmigración internacional. Oficina del Alto Comisionado para los Derechos Humanos, Ginebra, Suiza. Recuperado de https://www.ohchrorg/Documents/ Issues/Migration/MigrationHR_improvingHR_ReporSPt.pdf (En línea).

Ministerio de Asuntos Exteriores, Unión Europea y CoOperación. (2018). Las migraciones en África, Documentos Exteriores. Recuperado de http://www.exteriores.gob. es/Portal/es/PoliticaExteriorCooperacion/Africa/Documents/20180724_ARTICULO.pdf (En línea).

Molina GonzÁlez-Pumariga, R. (2004). La protección jurídica de la mujer trabajadora, Consejo Económico y Social, Madrid, pág. 130.

MoReno Nieto. JuAna (2009). Los contratos en origen de temporada: mujeres marroquíes en la agricultura onubense. Revista de Estudios Internacionales Mediterráneos REIM - № 7 - (Enero - Mayo 2009) ISSN: 1887- 4460.

Murciano AlváREz, G (2019). Nueva regulación en la contratación colectiva de extranjeros en origen en 2019. Recuperado de https://blog.sepin.es/2019/02/contratacioncolectiva-extranjeros/ (En línea).

NotiCIAS BANCARIAS (2020). Aprueban orden para la gestión colectiva de contratación en origen de 2020. Recuperado de https://noticiasbancarias.com/economia-y-finanzas/03/01/2020/aprueban-orden-para-la-gestion-colectiva-de-contratacion-enorigen-de-2020/201335.html (En línea).

Nueva TRIBUna (2018). Los criterios de contratación de mujeres marroquíes para la campaña de la fresa son "machistas y retrógrados". Recuperado de http://www.nuevatribuna.es/articulo/economia-social/andalucia-criterios-contratacion-campanafresa-son-retrogrados-machistas (En línea).

OfXAm InTERmón (2009). Trabajadoras de la fresa en Marruecos: un camino hacia la dignidad. Recuperado de https://www.oxfamintermon.org/es/programas-de-desarrollo/proyectos/proteccion-social-de-trabajadoras-de-fresa-en-marruecos (En línea). PúBLICo (2018). Una revista alemana denuncia violaciones a mujeres y abortos en los campos de fresa de Huelva. Recuperado de http://www.publico.es/sociedad/abuso-trabajadoras-migrantes-revista-alemana-denuncia-violaciones-mujeres-abortos-campos-fresa-huelva.html (En línea).

Selma Penalva, A. (2013). La protección jurídico-social de los colectivos especialmente vulnerables. Pág. 211. Murcia, España: Servicio de Publicaciones de la Universidad de Murcia (EDITUM).

Viveros CAlifornia (2017). El mercado Asiático quiere fresas andaluzas. Recuperado de http://viveroscalifornia.com/noticias/mercado-asiatico-plantas-fresa (En línea). 